\title{
Retinal Dopamine Mediates Multiple Dimensions of Light-Adapted Vision
}

\author{
Chad R. Jackson, ${ }^{1 \star}$ Guo-Xiang Ruan, ${ }^{1 \star}$ Fazila Aseem, ${ }^{2}$ Jane Abey, ${ }^{2}$ Karen Gamble, ${ }^{3}$ Greg Stanwood, ${ }^{4}$ \\ Richard D. Palmiter, ${ }^{5}$ P. Michael Iuvone, ${ }^{2}$ and Douglas G. McMahon ${ }^{1}$ \\ ${ }^{1}$ Department of Biological Sciences, Vanderbilt University, Nashville, Tennessee 37235, ${ }^{2}$ Departments of Ophthalmology and Pharmacology, Emory \\ University School of Medicine, Atlanta, Georgia 30322, ${ }^{3}$ Department of Psychiatry and Behavioral Neurobiology, University of Alabama-Birmingham, \\ Birmingham, Alabama 35294-0017, ${ }^{4}$ Department of Pharmacology, Vanderbilt University School of Medicine, Nashville, Tennessee 37232, and ${ }^{5}$ Howard \\ Hughes Medical Institute and Department of Biochemistry, University of Washington, Seattle, Washington 98195
}

Dopamine is a key neuromodulator in the retina and brain that supports motor, cognitive, and visual function. Here, we developed a mouse model on a C57 background in which expression of the rate-limiting enzyme for dopamine synthesis, tyrosine hydroxylase, is specifically disrupted in the retina. This model enabled assessment of the overall role of retinal dopamine in vision using electrophysiological (electroretinogram), psychophysical (optokinetic tracking), and pharmacological techniques. Significant disruptions were observed in high-resolution, light-adapted vision caused by specific deficits in light responses, contrast sensitivity, acuity, and circadian rhythms in this retinal dopamine-depleted mouse model. These global effects of retinal dopamine on vision are driven by the differential actions of dopamine D1 and D4 receptors on specific retinal functions and appear to be due to the ongoing bioavailability of dopamine rather than developmental effects. Together, our data indicate that dopamine is necessary for the circadian nature of light-adapted vision as well as optimal contrast detection and acuity.

\section{Introduction}

Dopamine is a key neurotransmitter that modulates the function of neural circuits supporting motor function, cognition, and vision. It is synthesized and released from specific populations of neurons, which, in the CNS, are principally located in a number of different brain regions and in the retina. Dopaminergic neurons convert tyrosine to L-3,4-dihydroxyphenylalanine (LDOPA) via tyrosine hydroxylase (TH) and L-DOPA to dopamine via aromatic L-amino acid decarboxylase. Secreted dopamine acts on target neurons and circuits through a family of G-proteincoupled receptors, which comprise two subfamilies, D1-like (D1 and D5) and D2-like (D2, D3, and D4) receptors that are positively and negatively linked to adenylyl cyclase, respectively. Dys-

Received Feb. 14, 2012; revised May 14, 2012; accepted May 19, 2012.

Author contributions: C.R.J., G.-X.R., G.S., P.M.I., and D.G.M. designed research; C.R.J., G.-X.R., F.A., and J.A. performed research; G.S. and R.D.P. contributed unpublished reagents/analytic tools; C.R.J., G.-X.R., F.A., J.A., K.G., P.M.I., and D.G.M. analyzed data; C.R.J., R.D.P., P.M.I., and D.G.M. wrote the paper.

This research was supported in part by grants from the National Institutes of Health R01EY15815, T32EY07135, P30EY008126, R01EY004864, P30EY006360, R01MH086629, and T32EY07092; the Katz Foundation; and an unrestricted departmental grant from Research to Prevent Blindness (RPB), New York. P.M.I. is a recipient of a Senior Scientific Investigator Award from RPB. Some experiments reported herein were conducted within the Vanderbilt Mouse Neurobehavioral Core laboratory.

${ }^{*}$ C.R.J. and G.-X.R. contributed equally to this work.

The authors declare no competing financial interests.

Correspondence should be addressed to either of the following P. Michael luvone, Department of Ophthalmology, Emory University, 1365B Clifton Road NE, Atlanta, GA 30322, E-mail: miuvone@emory.edu; or Douglas G. McMahon, Department of Biological Sciences, Vanderbilt University, 8268 BSB/MRBIII, 46521 st Avenue South, Nashville, TN 37235. E-mail: douglas.g.mcmahon@vanderbilt.edu.

G.-X. Ruan's present address: Schepens Eye Research Institute, Massachusetts Eye and Ear Infirmary, Harvard Medical School, Boston, MA 02114

DOI:10.1523/JNEUROSCI.0711-12.2012

Copyright $\odot 2012$ the authors $\quad 0270-6474 / 12 / 329359-10 \$ 15.00 / 0$ function of dopaminergic signaling in these pathways, or depletion of dopamine due to degeneration of dopaminergic neurons, is associated with mood disorders, cognitive defects, schizophrenia, and parkinsonism (Snyder, 1976; Diehl and Gershon, 1992; Kulisevsky, 2000; Taylor et al., 2009).

In the retina, dopamine synthesis and release are regulated by both light input and the retinal circadian clock, such that dopamine utilization is higher during light exposure and/or in the day (Iuvone et al., 1978; Doyle et al., 2002), suggesting that dopamine may mediate light-adaptive mechanisms and day-phase circadian processes in retinal function. Although much is known about the cellular and synaptic effects of dopamine in the retina, where it has been shown to modulate electrical coupling through gap junctions, transmission through glutamate and GABA receptors, voltage-gated ion channels, cAMP metabolism, and melatonin synthesis (Witkovsky, 2004; Iuvone et al., 2005), the overall effects of retinal dopamine on vision have not been elucidated. Disturbances in contrast sensitivity, visual-evoked potentials and electroretinographic (ERG) responses, and visual memory have all been documented in dopaminergic syndromes such as schizophrenia, addiction, and parkinsonism; however, in these conditions both brain and retinal dopamine are likely affected so it is not clear whether the observed effects on vision are central or retinal (Bodis-Wollner, 1990b; Masson et al., 1993; Lorea et al., 2010). Similarly, a limitation of studies manipulating retinal dopamine in animal models or in vitro occurs on the background of endogenous retinal dopamine levels (Bodis-Wollner, 1990a).

To investigate the overall role of retinal dopamine in vision, we have produced a mouse model in which the expression of $\mathrm{TH}$ is selectively disrupted in the retina, but conserved in the brain, 
resulting in retina-specific dopamine deficiency. These mice exhibit deficits in light-adapted ERG responses, contrast sensitivity, acuity, and retinal circadian rhythms; specific subsets of which can be mimicked by either dopamine D1 or D4 receptor (D1R and D4R) knock-out mice and rescued by specific D1R or D4R agonists. Thus, dopamine mediates multiple facets of lightadapted vision through two distinct dopaminergic receptor signaling pathways. Differential signaling that engages multiple dopamine receptor pathways also occurs in brain nuclei targeted by dopamine for motor function and reward, the striatum and nucleus accumbens (Ikemoto et al., 1997; Day et al., 2008), suggesting that parallel receptor signaling is a general feature of dopaminergic modulation of complex circuits in the CNS.

\section{Materials and Methods}

Generation of conditional Th mice. A loxP site was inserted into the BsaB1 site located $\sim 600 \mathrm{bp} 5^{\prime}$ of the transcription start site of the tyrosine hydroxylase (Th) gene. Another loxP site and a Frt-flanked SvNeo selectable gene were inserted into the Kpn1 site in the first intron of the Th gene. The targeting construct had $\sim 12 \mathrm{~kb}$ of $5^{\prime}$ flanking sequence and 7 $\mathrm{kb}$ of $3^{\prime}$ flanking sequence as well as a Pgk-DTA gene for negative selection. Linearized DNA was electroporated into AB1 embryonic stem cells. Correctly targeted events ( $\sim 20 \%$ of total) were detected by Southern blot of EcoR1-digested DNA using a probe just 3' of the short arm of the targeting construct. One clone transmitted the targeted allele through the germline. Mice bearing the targeted allele were bred with FLPer mice expressing the FLIP recombinase (Farley et al., 2000) to remove the Frt$\mathrm{S} v \mathrm{Neo}$ cassette. After removing the FLPer gene, the mice were backcrossed to C57BL/6 mice for multiple generations producing male and female experimental animals. All animal protocols were accordant with the guidelines established by the University of Washington Animal Care Committee, Emory University's Institutional Animal Care and Use Committee, Vanderbilt University Animal Care Division, and the National Institutes of Health Guide for the Care and Use of Laboratory Animals.

Two PCR primers ( $\mathrm{a}$ and $\mathrm{b}$ ) were used for routine genotyping of the conditional allele, which amplify $150 \mathrm{bp}$ region for the wild-type (WT) Th allele and $200 \mathrm{bp}$ region for the $T h^{\text {lox/lox }}$ allele. To distinguish WT $\left(T h^{+/+}\right)$, hemizygous $\left(T h^{\text {lox } /+}\right)$, and homozygous mice $\left(T h^{\text {lox/lox }}\right)$, PCR genotyping of DNA extracted from mouse tails was performed using primers a and c, which yield a single $\sim 1000$ bp band for $T h^{\text {lox } / l o x}$ mice, a single $\sim 900$ bp band for $\mathrm{Th}^{+/+}$mice, and two bands for $\mathrm{Th}^{\text {lox/+ }}$ mice. Primer sequences were as follows: a, 5' -GTTGCAGGCTGTGTCTTC-3'; b, 5' -CCAGTGTATGTGCTGGCAC-3'; and c, 5' -GGACCCACAGAA GCCTGGCA-3'. PCR was first incubated at $98^{\circ} \mathrm{C}$ for $2 \mathrm{~min}$, followed by 32 cycles of $98^{\circ} \mathrm{C}$ for $30 \mathrm{~s}, 56^{\circ} \mathrm{C}$ for $30 \mathrm{~s}$, and $72^{\circ} \mathrm{C}$ for $1 \mathrm{~min}$.

Generation of retina-specific Th knock-out mice. Chx10-Cre mice purchased from The Jackson Laboratories were crossed with conditional Th mice to obtain $T h^{l o x / l o x}$ mice that carry no copies or a single copy of the Chxilo-Cre gene and mice that carry one $\left(T h^{\text {lox } /+}\right)$ or two $\left(T h^{\text {lox } / l o x}\right)$ alleles. These transgenic mice express Cre recombinase under the control of the Chx10 promoter which is expressed in all retinal neural progenitor cells (Graw, 1996). PCR genotyping for the Chx10-Cre transgene was performed using multiplex PCR and primers $5^{\prime}$-GCCTAGCCGAGGGA GAGCCG-3' and 5' -TGTGACTTGGGAGCTCTGCAGC-3', which amplify the 155 bp region for the WT Chx10 allele and 5'-GGGCACCTGG GACCAACTTCACGA-3' and 5'-CGGCGGCGGTCACGAACTCC-3', which amplify $\sim 750$ bp for the Chx10-Cre allele (Rowan and Cepko, 2004). PCR was first incubated at $94^{\circ} \mathrm{C}$ for $3 \mathrm{~min}$, followed by 35 cycles of $94^{\circ} \mathrm{C}$ for $30 \mathrm{~s}, 69^{\circ} \mathrm{C}$ for $1 \mathrm{~min}$, and $72^{\circ} \mathrm{C}$ for $1 \mathrm{~min}$. Dopamine, $3,4-$ dihydroxyphenylacetic acid (DOPAC), and norepinephrine were measured in retina and brain of the different genotypes by HPLC with coulometric detection, as previously described (Pozdeyev et al., 2008).

Dopamine D1, D4, and D5 knock-out mice (D1RKO, D4RKO, D5RKO). D1RKO mice were purchased from The Jackson Laboratories and maintained on the C57BL6 background. Genotypes were confirmed by PCR analysis, using minor variants of published methods (Stanwood et al.,
2005) and the following primers: (1) 5'-AAAGTTCCT TTAAGATGTC CT-3' and (2) 5' -TGGTGGCTGGAAAACATCAGA-3' (used to detect D1 WT band and Neo insert). D4RKO mice (Rubinstein et al., 1997) were genotyped using the following primers: (1) 5' -CATGGACGTCAT GCTGTGCA-3', (2) 5'-CGGACGAGTAGACCACATAG-3' (used to detect WT band), and (3) 5'-GCCCGGTTCTTTTTGTCAAG-3' (used with second primer to detect Neo insert). D5RKO mice were also purchased from The Jackson Laboratories and genotypes were determined by PCR using the following primers sets: (1) $5^{\prime}$-ACTCTCTTAATCGT CTGGACCTGG-3' (also used for KO band), (2) 5' -GGAGGAGATACG GCGGATCTGAAC-3' (used to detect WT band), and (3) 5' -TGATCA ACTAGTGCCCGGGCGGTA-3' (used with first primer to detect D5KO band).

ERG. Dark- and light-adapted ERG recordings were performed as previously described (Cameron et al., 2008a,b) with minor modifications. All mice were tested in the LKC Technologies UTAS visual electrodiagnostic test system. Before testing, mice were housed on a $12 \mathrm{~h} \mathrm{light/}$ dark cycle and dark adapted according to their particular testing condition. Mice were anesthetized with an intraperitoneal injection of ketamine $(70 \mathrm{mg} / \mathrm{kg})$ and xylazine $(7 \mathrm{mg} / \mathrm{kg})$ and their pupils dilated with $1 \%$ tropicamide and $1 \%$ cyclopentolate. Their eyes were kept moist with $10 \%$ methylcellulose eye drops. Core body temperature was maintained at $\sim 37.0^{\circ} \mathrm{C}$ using a thermostatically controlled heating pad regulated by a rectal temperature probe (Model TC-1000 Temperature Controller; CWE). Needle electrodes placed in the cheek and the tail served as reference and ground leads, respectively. A DTL fiber or platinum contact lens electrodes were used for recording ERG responses. Dark-adapted ERG responses were differentially amplified and filtered (bandwidth: 0.3-500 $\mathrm{Hz}$ ), with responses digitized at $1024 \mathrm{~Hz}$. The recording epoch was 250 $\mathrm{ms}$, with a $20 \mathrm{~ms}$ prestimulation baseline. Stimulus flashes were presented in a LKC BigShot ganzfeld (LKC Technologies). A total of 14 stimulus intensities, ranging from -3.60 to $1.37 \log \mathrm{cd}^{*} \mathrm{~s} / \mathrm{m}^{2}$, were used under dark-adapted conditions. Each flash duration was $20 \mu$ s and stimuli were presented in order of increasing intensity. As flash intensity increased, retinal dark adaptation was maintained by increasing the interstimulus interval from 10 to $100 \mathrm{~s}$.

Before light-adapted testing, one flash of light under dark-adapted conditions was given to assess the animal for a normal retinal response (normal a-wave and b-wave; mice that exhibited abnormal responses were excluded from the experiment). For light-adapted ERGs a steady background adapting field $\left(40 \mathrm{~cd} / \mathrm{m}^{2}\right)$ was presented inside the UTAS BigShot ganzfeld to saturate the rod photoreceptors. Simultaneously, $0.90 \log \mathrm{cd}^{*} \mathrm{~s} / \mathrm{m}^{2}$ bright light flashes were presented at $0.75 \mathrm{~Hz}$ during a 20 min period of light adaptation. Data were collected in 2.6 min averaged bins, totaling eight bins. All other test parameters were similar to the dark-adapted ERG. The a-wave and b-wave amplitudes and implicit times were analyzed off-line. ERG waveforms were filtered (low pass 60 $\mathrm{Hz}$ ) to remove the influence of oscillatory potentials. The amplitude of the a-wave was measured from the prestimulus baseline to trough and that of the b-wave from the trough of the a-wave to peak of the b-wave. The implicit times were measured from flash onset to the peak of each wave.

Treatment with L-DOPA. L-DOPA $(1 \mathrm{mg} / \mathrm{ml})$ was administered in drinking water containing $0.25 \%$ ascorbic acid in applicable experiments. Solutions were prepared fresh daily and shielded from light. Pregnant and nursing dams had ad libitum access to L-DOPA/ascorbate or to ascorbate alone as a vehicle control. After weaning, pups continued to receive L-DOPA and ascorbate for 1.5-2.5 months. Some mice were subsequently withdrawn from L-DOPA for 1 month before testing.

Retinal bioluminescence measurements. Chx10-Cre:Th ${ }^{\text {lox/lox }}$ mice were crossed with mice harboring the Per2 ${ }^{\text {Luc }}$ reporter gene (Yoo et al., 2004) (a gift from Dr. J. Takahashi, University of Texas Southwestern Medical Center) to assess what role dopamine plays in maintaining retinal circadian rhythms. In Per2 ${ }^{L u c}$ knock-in mice, expression of a PER2:: Luciferase fusion protein is robustly rhythmic in the retina. After breeding, we obtained Chx10-Cre:Th ${ }^{\text {lox } /+}, C h x 10-C r e: T h^{l o x} /$ lox , and $T h^{\text {lox } / l o x}$ mice all containing one allelic copy of the $\mathrm{Per} 2^{\mathrm{Luc}}$ gene reporter. Mouse genotypes were determined by using PCR (Per2 ${ }^{\text {Luc }}$ genotyping; Primer 1: 5'CTGT GTTTACTGCGCGAGT3', Primer 2: 5'GgGTCCATGTGA TTAG 
AAAC3', Primer 3: 5'TAAAACCGGGAGGTAGATGAGA3'; knock-in band at $680 \mathrm{bp}$, WT band at $229 \mathrm{bp}$; Temperature cycles: Step $1-94^{\circ} \mathrm{C} 7.5$ min, Step $2-94^{\circ} \mathrm{C}$ for $1 \mathrm{~min}$, Step $3-55^{\circ} \mathrm{C} 1 \mathrm{~min}$, Step $4-72^{\circ} \mathrm{C}$ for $1 \mathrm{~min}$ [ $35 \times$ cycles between Steps 2 and 4], Step $5-72^{\circ} \mathrm{C}$ for $15 \mathrm{~min}$, Step 6-Hold at $\left.4^{\circ} \mathrm{C}\right)$.

Retinal explant culture and bioluminescence measurements were performed as previously described (Ruan et al., 2008). Two-month-old mice were killed at $\sim 4 \mathrm{~h}$ after lights on in the mouse colony. Eyes were enucleated and placed in HBSS (Invitrogen). Retinas were isolated and each retina was cut into two pieces. Each piece of retina was placed, ganglion cell layer up, on Millicell culture membrane (Millipore) and gently flattened. The membrane, along with the retinal culture, was first transferred to $1.0 \mathrm{ml}$ of Neurobasal medium (Invitrogen) supplemented with $2 \mathrm{~mm}$ L-glutamine (Sigma-Aldrich), 2\% B27 (Invitrogen), $25 \mathrm{U} / \mathrm{ml}$ penicillin, and $25 \mu \mathrm{g} / \mathrm{ml}$ streptomycin (Invitrogen). After $24 \mathrm{~h}$ incubation in a humidified incubator at $37^{\circ} \mathrm{C}$ and $5 \% \mathrm{CO}_{2}$, the membrane and retinal culture were transferred to $1.0 \mathrm{ml}$ of Medium 199 (Sigma-Aldrich) supplemented with $0.7 \mathrm{~mm}$ L-glutamine, $4 \mathrm{~mm}$ sodium bicarbonate (Sigma-Aldrich), $10 \mathrm{~mm}$ HEPES (Sigma-Aldrich), $20 \mathrm{~mm}$ D-glucose (Sigma-Aldrich), 2\% B27, $0.1 \mathrm{~mm}$ beetle luciferin (Promega), $25 \mathrm{U} / \mathrm{ml}$ penicillin, and $25 \mu \mathrm{g} / \mathrm{ml}$ streptomycin. Bioluminescence from the retinal explant cultures were then measured with a LumiCycle (Actimetrics).

Visual psychophysical testing. Ctrl, rTHKO, D1RKO, D4RKO, D5RKO mice, and WT controls were all tested for visual behavior analysis (acuity threshold and contrast sensitivity) in the OptoMotry device (Cerebral Mechanics) (Prusky et al., 2004). As described by Prusky et al. (2004), mice were placed on a platform in the OptoMotry, without movement restriction. Through a video feed the observer tracked the reflexive head movements of the mouse in response to a rotating sine-wave gradient projected by four LCD monitors surrounding the platform. Tracking was defined as when head movements tracked in the same direction and speed as the rotation of the sine-wave gradient. Visual acuity threshold was measured using a staircase method with a random/separate display of spatial frequencies and rotation direction, respectively, of the sinusoidal gradient. This procedure automatically increased the spatial frequency of the sine-wave gradient until the observer could no longer determine head-tracking movements. This spatial frequency was deemed the animal's visual acuity threshold.

Similarly, contrast sensitivity was measured by observation of headtracking movements to a sine-wave gradient; however, the black and white gradients were systematically reduced from $100 \%$ contrast until animal head-tracking movements were no longer observed. The last contrast level where the animal could track was deemed its contrast sensitivity threshold. As described by Prusky et al. (2004) we measured contrast sensitivity threshold at six spatial frequencies $(0.031,0.064,0.092,0.103$, 0.192 , and 0.272 cycles/degree). The contrast sensitivity was calculated using a Michelson contrast from the screen's luminance (maximum minimum) $/($ maximum + minimum) as previously described (Prusky et al., 2006).

Statistical analyses. For analysis of the HPLC results of retinal dopamine levels, a one-way ANOVA was used with Fisher's least significant difference (LSD) test for post hoc comparisons. For analysis of the $\mathrm{TH}$-positive cell counts, the variances among groups were not equal as indicated by a significant Levene's test; therefore, a nonparametric Kruskal-Wallis test followed by Dunnett's T3 post hoc test for unequal variances was used.

ERG data were analyzed with a three-way linear mixed model (Genotype $\times$ Circadian Time $[\mathrm{CT}] \times$ Intensity, or Genotype $\times \mathrm{CT} \times$ Light Adaptation Time) with repeated measures on Intensity or Time during light adaptation, using a first-order autoregressive covariance structure depending on experimental conditions. For post hoc comparison of the interactions, planned comparisons of CT within each genotype at each time of adaptation were made with independent samples or paired $t$ tests (as appropriate) and Bonferroni-corrected $\alpha$. For all other tests, $\alpha=$ 0.05 . Visual acuity and contrast sensitivity tests were analyzed using a one-way and two-way with repeated measures ANOVAs where applicable depending on genotypes and treatments. Post hoc comparisons of interactions were performed with the Student-Newman-Kuels method. Significance levels were set at $p=0.05$.
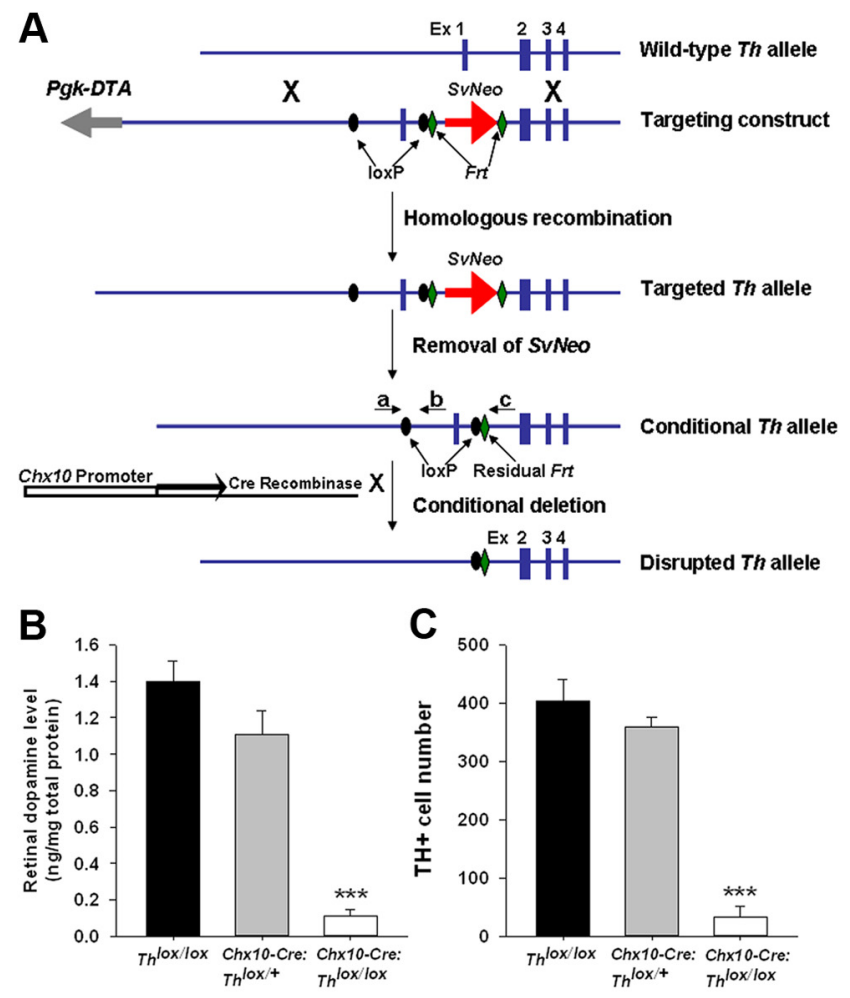

[Ctrl] [Ctrl] [rTHKO]

[Ctrl] [Ctrl] [rTHKO]

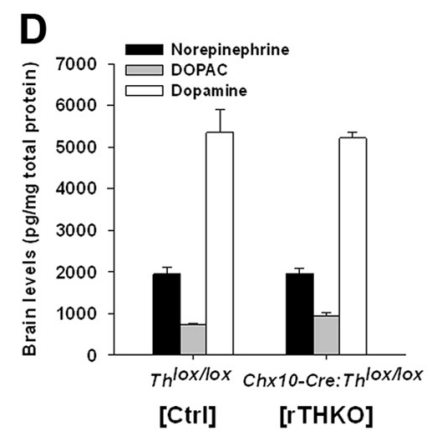

Figure 1. Generation of retina-specific Th knock-out mice. $A$, Generation of conditional $T h$ mice. Blue boxes, exons (Ex); gray arrow, negative selection marker Pgk-DTA; red arrow, neomycin resistance gene under the control of the Sv40 promoter (SvNeo); black ovals, loxP sites; green diamonds, Frt sites; black arrows depict Cre recombinase under the control of the Chx10 promoter (white box). Primers a plus b amplify $150 \mathrm{bp}$ for the WT Th allele and $200 \mathrm{bp}$ for the $T h^{10 x}$ allele, while primers a plus cyield a single $\sim 1000$ bp band for homozygous mice, a single $\sim 900$ bp band for WT mice, and two bands for hemizygous mice. $B$, Retinal dopamine levels in $\mathrm{Ctrl}\left(\mathrm{Th}^{\text {lox/lox}}\right)$, hemizygous-Ctrl (Chx 10-Cre: $\left.\mathrm{Th}^{\text {lox/++}}\right)$, and homozygous-rTHK0 mice (Chx10-Cre: $T h^{\text {lox/lox }}$ ) as measured by HPLC. HPLC was performed as described by (Ruan et al., 2008). Data are represented as means \pm SEM $(n=4)$. C, TH-immunoreactive $\left(\mathrm{TH}^{+}\right)$cell number in the $\mathrm{Ctrl}$ $\left(\mathrm{Th}^{10 x / 10 x}\right)$, $\mathrm{Ctrl}\left(\mathrm{Chx} 10-\mathrm{Cre}: \mathrm{Th}^{10 \mathrm{x} /+}\right)$, and rTHKO (Chx10-Cre: $\left.\mathrm{Th}^{10 \times / 10 x}\right)$ mouse retinas. Immunocytochemistry was performed as described by (Ruan et al., 2008). Data are represented as means \pm SEM $\left({ }^{* * *} p<0.01, n=4\right.$ mice). D, Brain dopamine (white bars), DOPAC (gray bars), and norepinephrine (black bars) levels measured in $\mathrm{Ctrl}\left(\mathrm{Th}^{\text {lox/lox }}\right), \mathrm{Ctrl}\left(\mathrm{Chx} \times \mathrm{10}-\left(\mathrm{re}: \mathrm{Th}^{\text {lox/+}}\right)\right.$, and rTHKO (Chx10-Cre:Th ${ }^{\text {lox/lox }}$ ) by HPLC; no significant change.

\section{Results}

\section{Retina-specific depletion of dopamine}

We generated a mouse line harboring a conditional allele of $T h$, the rate-limiting enzyme in dopamine synthesis. This floxed $T h$ allele is subject to excision using the Cre/loxP recombination system (Abremski and Hoess, 1984; Hamilton and Abremski, 1984; Orban et al., 1992), with loxP sites flanking the promoter and first exon of the Th gene (Fig. $1 A$ ). To achieve retina-specific 
Th excision, we crossed conditional Th mice $\left(T h^{\text {lox/lox }}\right)$ with Chx10-Cre mice, which express Cre recombinase in retinal neural progenitor cells (Rowan and Cepko, 2004), and then bred the resulting Chx10-Cre: $\mathrm{Th}^{\text {lox/+ }}$ mice with each other to obtain the following genotypes: $T h^{+/+}, T h^{l o x /+}$, and $T h^{l o x / l o x}$ mice, with or without Chx10-Cre. Genotypes indicated as Cre positive carried a single copy of the Chx10-Cre gene and either no floxed Th alleles $\left(T h^{+/+}, \mathrm{WT}\right)$, one floxed and one WT Th allele $\left(T h^{l o x /+}\right.$, hemizygous), or two floxed $T h$ alleles ( $T h^{\text {lox } / l o x}$, homozygous). Mice were maintained on a C57/BL/6 background.

Retinal dopamine levels measured with HPLC revealed no significant difference between Chx10-Cre-null $T h^{\text {lox/lox }}$ and Chx10-Cre: $T h^{\text {lox/+ }}$ mice, whereas dopamine levels in retinas from Chx10-Cre:Th ${ }^{\text {lox/lox }}$ mice in which both Th alleles were subject to excision were reduced by $\sim 90 \%$ (Fig. $1 B ;{ }^{* *} p<0.001$ for both). Consistent with the HPLC data, there was no significant difference between $T h^{l o x / l o x}$ and $C h x 10-C r e: T h^{l o x /+}$ mice in the number of retinal TH-positive cells measured by immunohistochemistry, while $\mathrm{TH}$-positive cell counts in Chx10-Cre: $\mathrm{Th}^{\text {lox/lox }}$ retinas were reduced by $\sim 90 \%$ (Fig. $1 C$; ${ }^{* *} p<0.01$ for both). While retinal dopamine was markedly reduced, brain dopamine, DOPAC, and norepinephrine levels were preserved in Chx10-Cre:Th ${ }^{\text {lox } / l o x}$ mice (Fig. 1D). In addition Chx10-Cre:Th ${ }^{l o x / l o x}$ mice were indistinguishable from $T h^{l o x / l o x}$ mice in body weight and gross behavior (data not shown). Together, these results indicate that there is retina-specific depletion of dopamine and its synthetic enzyme TH in Chx10-Cre:Th ${ }^{l o x / l o x}$ mice. Hereafter (see Results and Discussion) $\mathrm{Th}^{+/+}, \mathrm{Th}^{\text {lox/lox }}$, and Chx10-Cre: $\mathrm{Th}^{\text {lox/+ }}$ mice will be referred to as Control (Ctrl), while Chx10-Cre: $T h^{\text {lox/lox }}$ mice will be referred to as retinal TH knock-outs (rTHKO).

\section{Dopamine depletion blunts rhythmic light-adapted ERG, contrast sensitivity, and acuity}

We assessed the effects of retina-specific dopamine depletion on retinal function and vision using the following: (1) the ERG to measure overall retinal electrical activity in response to light and (2) optokinetic tracking (OKT) based on the optokinetic reflex (Prusky et al., 2004) to measure visual contrast sensitivity and acuity threshold. The positive b-wave of the ERG recorded under photoptic (light-adapted) conditions is regulated by the retinal circadian clock (Barnard et al., 2006; Storch et al., 2007; Cameron et al., 2008b); thus, we assayed the ERG over CT in animals maintained in constant darkness (DD). Dark-adapted ERG intensityresponse curves were recorded on the second day in constant darkness (DD2) following 42 or 54 h of dark adaptation, where mice were presented with light flashes of increasing intensity on a completely dark background. This particular test measures overall retinal electrical function, mainly assessing the rod and cone photoreceptors and ON-bipolar cell responses to flashes of increasing light intensity. The recording times correspond to midday and midnight during the light cycle on which the mice had been maintained before entry into DD and are designated as CT6 and CT18, respectively. Dark-adapted a-wave and b-wave amplitudes (Fig. $2 A, B$ ) and implicit times (data not shown) in rTHKO mice were not significantly different from those of controls. In agreement with previous results (Cameron et al., 2008a), there was no evidence of circadian modulation of the dark-adapted ERG in either genotype at their respective recording time points (Fig. $2 A, B$; b-wave: $\mathrm{A}, p=0.67$ and $\mathrm{B}, p=0.60$, respectively; a-wave: $A, p=0.21$ and $B, p=0.60$, respectively). The intact dark-adapted ERG a-waves and b-waves suggest that retinal dopamine deficiency does not inhibit the function of
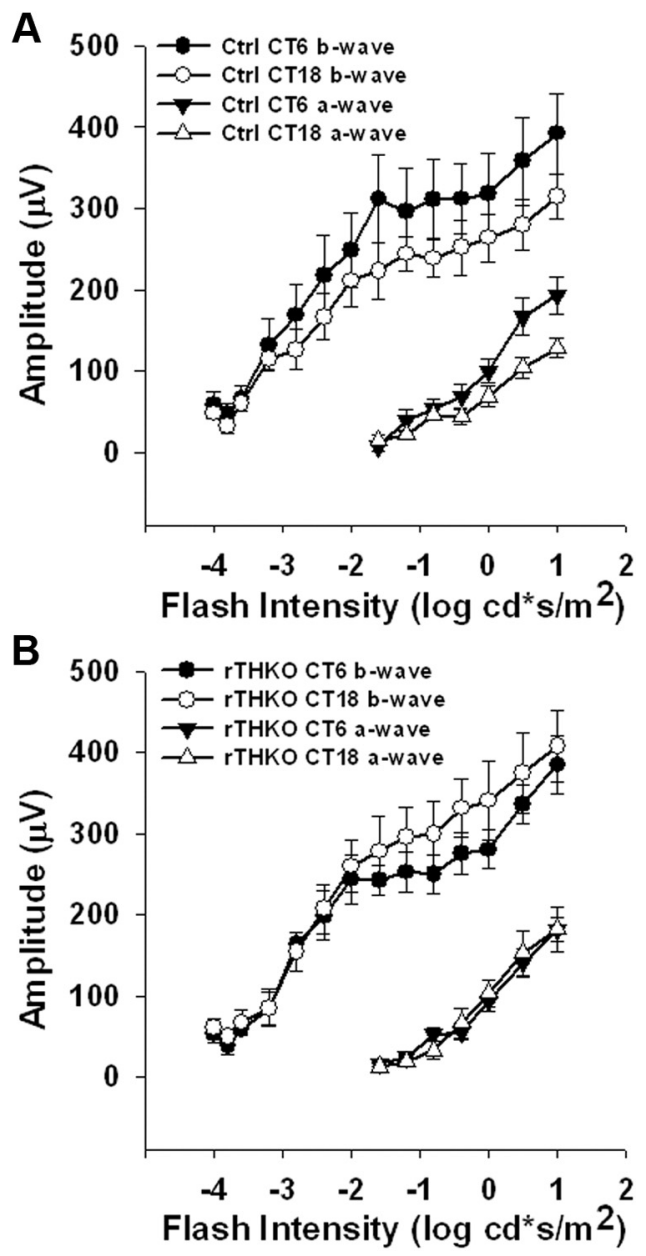

Figure 2. Dark-adapted ERG does not show a circadian response. $\boldsymbol{A}-\boldsymbol{B}$, Dark-adapted ERG, recorded during DD2, a-wave (triangles) and b-wave (circles) amplitudes at CT 6 (filled circles or triangles) or CT 18 (open circles or triangles) plotted as a function of log intensity in $\mathrm{Ctrl}(\boldsymbol{A})$ or rTHKO $(\boldsymbol{B})$ mice. A three-way ANOVA revealed no significant effect of CT or genotype on either b-wave or a-wave amplitudes (b-wave: $F_{(1,29)}=0.19$ and 0.28 , respectively, $p>0.05$; a-wave: $F_{(1,24)}=1.67$ and 0.29 , respectively, $p>0.05 ; n=6$ mice for each). Neither the b-wave implicit time nor the a-wave implicit time showed a significant difference between CT 6 and CT18 in both genotypes (data not shown).

rod photoreceptors (a-wave), ON-bipolar cells (b-wave) or synaptic transmission from rods to ON-bipolar cells.

In contrast to the dark-adapted ERG, the light-adapted ERG showed circadian regulation that was reduced in amplitude in retinal dopamine-deficient mice (Fig. $3 A, B$ ). In this test lightadapted ERGs assessed the retina's ability to adapt to a change in background illumination, indicative of the transition from nighttime to daytime vision. Light-adapted ERGs were obtained in the presence of rod-saturating, light-adapting background illumination from Ctrl and rTHKO mice at CT6 and CT18 on the first and second day in DD (DD1 and DD2; dark-adaptation times of 18, 30,42 , and $54 \mathrm{~h}$ ). Both Ctrl and rTHKO mice exhibited circadian regulation of the ERG during DD1, displaying significantly elevated light-adapted b-wave amplitudes during mid-subjective day (CT6) versus mid-subjective night (CT18) (Fig. 3A, $p<$ 0.01 ). However, the overall light-adapted b-wave amplitudes of rTHKO mice were significantly reduced and the amplitude of the day/night rhythm was damped compared with Ctrl mice during DD1 (Fig. 3A; Ctrls vs rTHKO, $p<0.007$ at each level of light adaptation time, Bonferroni-corrected $\alpha$ ). Light-adapted ERGs during DD2 exhibited significant main effects of adaptation time, 
A
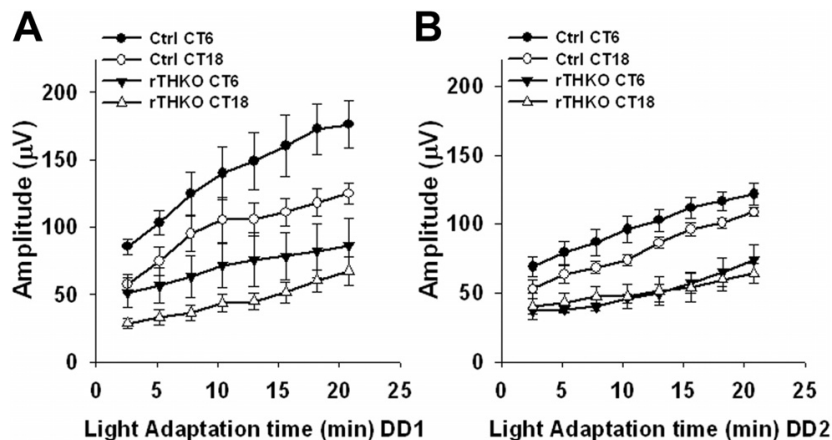

Figure 3. Light-adapted ERG amplitudes are circadian and controlled by retinal dopamine. $\boldsymbol{A}, \boldsymbol{B}$, Light-adapted ERG b-wave amplitudes at CT 6 (filled circles and triangles) or CT 18 (open circles and triangles) plotted as a function of light adaptation time in Ctrl or rTHKO mice during DD1 $(\boldsymbol{A})$ or DD2 $(\boldsymbol{B}) . \boldsymbol{A}, A$ two-way interaction was shown for Genotype $\times$ Light Adaptation Time $\left(F_{(7,98)}=3.2, p<0.01\right)$, such that $C$ trl mice had significantly higher amplitudes compared with rTHKO mice at each level of light adaptation ( $p<0.007$, Bonferroni-corrected $\alpha$ ). The Genotype $\times C \mathrm{C}$ interaction was not significant $\left(F_{(1,57)}=0.9, p>0.05\right)$. A main effect of CT showed a significant day/night difference during DD1 for both genotypes $\left(F_{(1,57)}=20.0, p<0.01\right) . \boldsymbol{B}$, In DD2, there was a significant two-way interaction for Genotype $\times \mathrm{CT}\left(F_{(1,36)}=7.4, p<\right.$ $0.01)$. Significant day/night differences were observed for Ctrl mice $(p<0.025$, Bonferronicorrected $\alpha$ ); however, day/night differences were not observed in rTHKO mice ( $p>0.025$, Bonferroni-corrected $\alpha$ ).

genotype, and CT (Fig. 3B; $p<0.01, p<0.01$, and $p<0.05$, respectively). During DD2, Ctrl mice continued to show circadian regulation of the light-adapted b-wave, with elevated response amplitude at CT 6 versus CT 18 (Fig. $3 B ; p<0.025$, Bonferroni-corrected $\alpha$ ); in contrast, circadian regulation of the ERG was abolished in $\mathrm{rTHKO}$ mice during DD2, with these mice exhibiting significantly lower amplitude responses at both CT6 and CT18, as compared with circadian night responses observed at CT18 in the Ctrls (Fig. 3B; $p>0.025$, Bonferroni-corrected $\alpha$ ). These findings show that mice lacking retinal dopamine were unable to maintain the circadian rhythm of the light-adapted b-wave amplitude with specific loss of the day-phase elevation in response amplitude. It was also noted that while the light-adapted b-wave circadian rhythm was disrupted in rTHKO mice, the ERG still displayed adaptation to the background light stimulus, exhibiting increases in amplitude with time in the background light similar to the ERG of control mice. There were no significant effects of genotype or of $\mathrm{CT}$ on b-wave-implicit times during DD1or DD2 (data not shown).

To further examine the effects of retinal dopamine depletion on vision, we used OKT of a rotating sine-wave gradient with varying contrast or spatial frequency to assess contrast sensitivity and visual acuity threshold (Prusky et al., 2004). Spatial contrast sensitivity functions (CSFs), measuring contrast sensitivity, were significantly reduced in rTHKO mice at three of the six tested spatial frequencies when compared with Ctrl mice (Fig. 4A; ${ }^{* *} p<0.001$ at $0.064,0.092$, and 0.103 cycles/degree). Thus, contrast sensitivity is significantly reduced when retinal dopamine is depleted. Visual acuity thresholds were also measured for these genotypes and acuity was significantly reduced $(\sim 8.0 \%)$ in rTHKO mice when compared with Ctrl mice (Fig. $4 B ;{ }^{*} p<0.05$ ).

The loss of circadian regulation of the light-adapted ERG observed in dopamine-deficient retinas could be due to stoppage of the retinal circadian clock (Storch et al., 2007), or due to retention of clock function but loss of synchrony or communication from the clock to retinal cell populations (Ruan et al., 2008). To test if genetic dopamine depletion had stopped or altered molecular circadian rhythms in the retina, we crossed the conditional
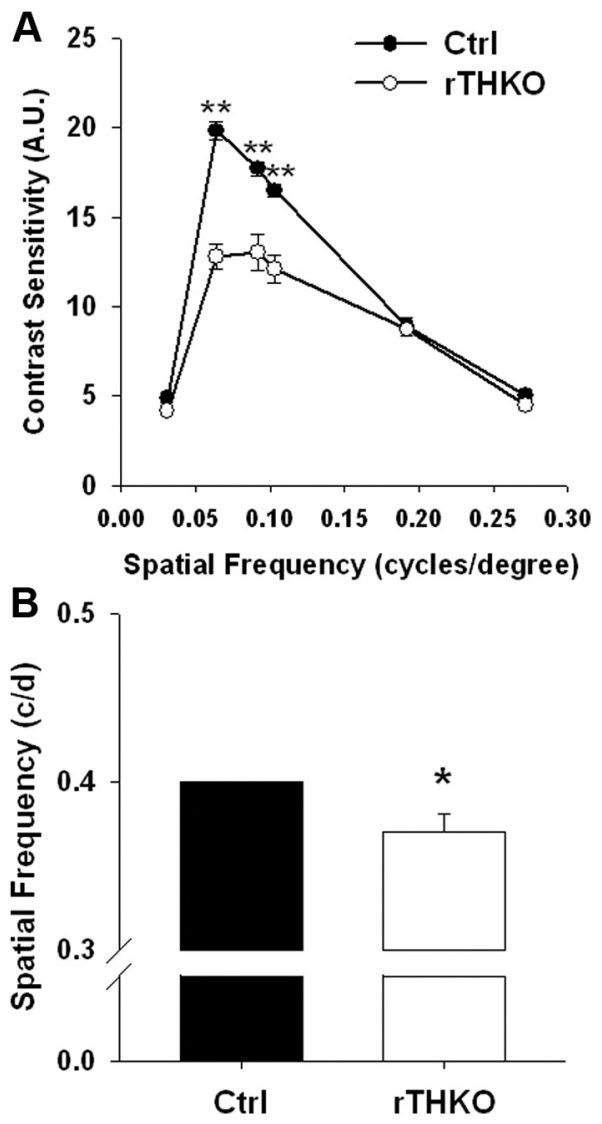

Figure 4. rTHKO mice displayed significant declines in visual parameters. $\boldsymbol{A}$, Contrast sensitivity was significantly reduced in rTHKO mice at three of the six tested spatial frequencies $\left({ }^{* *} p<0.01\right.$ at $0.064,0.092$, and 0.103 cycles/degree, two-way ANOVA, $n=4-6$ mice). $\boldsymbol{B}$, Acuity threshold was significantly lower in rTHKO mice $\left({ }^{*} p<0.05\right.$, two-way ANOVA, $n=4-8$ mice) compared with control mice. All data are represented as means \pm SEM.

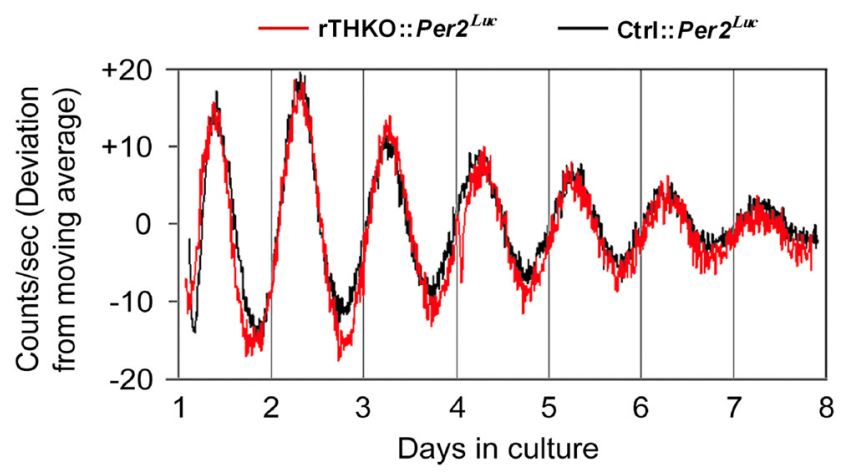

Figure 5. Retinal bioluminescence rhythms persist in retina-specific dopamine-deficient mice. Retinal explants sampled from Ctrl:Per2 ${ }^{\text {Luc }}$ (black lines) or rTHK0:Per2 ${ }^{\text {Luc }}$ (red lines). Data shown were baseline corrected by calculating a $24 \mathrm{~h}$ moving average of the raw data, and then the deviation from the moving average was plotted as a function of days in culture.

Th mouse lines with Per2 ${ }^{L u c}$ circadian reporter mice (Yoo et al., 2004) and then assayed for molecular circadian rhythms in retinal explants by bioluminescence using our previously established methods (Ruan et al., 2008). Retinal explants from rTHKO: $\mathrm{Per} 2^{\mathrm{Luc}}$ mice exhibited robust circadian rhythms in bioluminescence similar to Ctrl:Per2 ${ }^{\text {Luc }}$ mice (Fig. 5). This result indicates that retinal circadian rhythms at the molecular level are intact in these chronically dopamine-depleted retinas, as they are in retinas acutely depleted of dopamine by pharmacological treatments 
(Ruan et al., 2008), and suggests that the loss of circadian regulation of the ERG in the absence of dopamine is due to altered coupling of retinal oscillators or altered coupling of oscillators to functional rhythms, not to loss of rhythmicity itself.

\section{Effects of retinal TH deficiency are rescued by L-DOPA treatment}

The Chx10-Cre transgene is expressed in retinal neural progenitors early in retinal development (Rowan and Cepko, 2004); therefore, the visual effects observed in adult rTHKO mice could be due to the reduced concentration of retinal dopamine at the time of measurement, or due to altered retinal development in the absence of dopamine. To differentiate between these possibilities we restored the ability of rTHKO mice to synthesize retinal dopamine by providing L-DOPA $(1 \mathrm{mg} / \mathrm{ml}$; the product of TH enzymatic activity and proximal substrate for dopamine synthesis) in the drinking water (containing $0.25 \%$ ascorbate) of pregnant and nursing dams and of weaned mice. The offspring were tested for light-adapted ERG, CSF, and visual acuity threshold as mentioned above, while mice were either maintained on or removed from L-DOPA treatment. A second cohort of rTHKO mice received ascorbate vehicle in their drinking water as a control. For light-adapted ERG analysis, three-way ANOVA revealed significant main effects of Light Adaptation Time, Treatment type, and CT, as well as a significant Treatment $\times$ CT interaction (Fig. $6 A, B ; p<0.01$ for each main effect and the interaction). Post hoc analysis revealed that the rTHKO L-DOPA-treated group had significant day/night differences in their light-adapted ERG responses between CT6 and CT18 in DD2 (Fig. 6A, B; $p=0.005$ ), but did not increase the amplitude of the day-phase ERG sufficiently to fully restore the light-adapted ERG rhythmic amplitude level in rTHKO mice (Fig. 6A; $p=0.004$, Bonferroni-corrected $\alpha)$ to Ctrl levels. This could be due to mice drinking more water (containing L-DOPA) during the subjective night hours when they are more active. rTHKO L-DOPA-treated mice displayed significant increases in their light-adapted b-wave amplitude at CT18 when compared with the rTHKO ascorbate-treated group (Fig. $6 B ; p<0.004)$. In addition, L-DOPA treatment prevented the loss of contrast sensitivity (Fig. $6 C$; ${ }^{*} p<0.001$ ) and visual acuity threshold (Fig. $6 D ;{ }^{*} p<0.05$ ) in rTHKO mice. In all instances withdrawal of L-DOPA caused light-adapted ERG, CSF, and acuity thresholds to return to the level of ascorbate-treated controls (Figs. 6A, $B, 4 A, B$ ). These data suggest that the visual effects observed in rTHKO mice are primarily mediated by the bioavailability of dopamine at the time of measurement rather than by altered development. They do not, however, preclude developmental effects of retinal dopamine not assayed by our tests.

Differential actions of dopamine on vision through dopamine D1 and D4 receptors

In the mouse retina dopamine exerts its actions through four (D1, D2, D4, and D5) of the five mammalian dopamine receptor subtypes (Jackson et al., 2009). To investigate the receptor mechanisms underlying the visual actions of dopamine we tested dopamine D1, D4, and D5 knock-out mice (D1RKO, D4RKO, and D5RKO) for deficits in light-adapted ERG, CSF, and visual acuity threshold. D5RKO mice were equivalent to control mice in their light-adapted ERG regulation, CSFs, and visual acuity (data not shown); however, D4RKO and D1RKO mice exhibited specific and distinct visual deficits.

During DD1, the overall light-adapted ERG was significantly reduced in D4RKO mice when compared with WT control mice
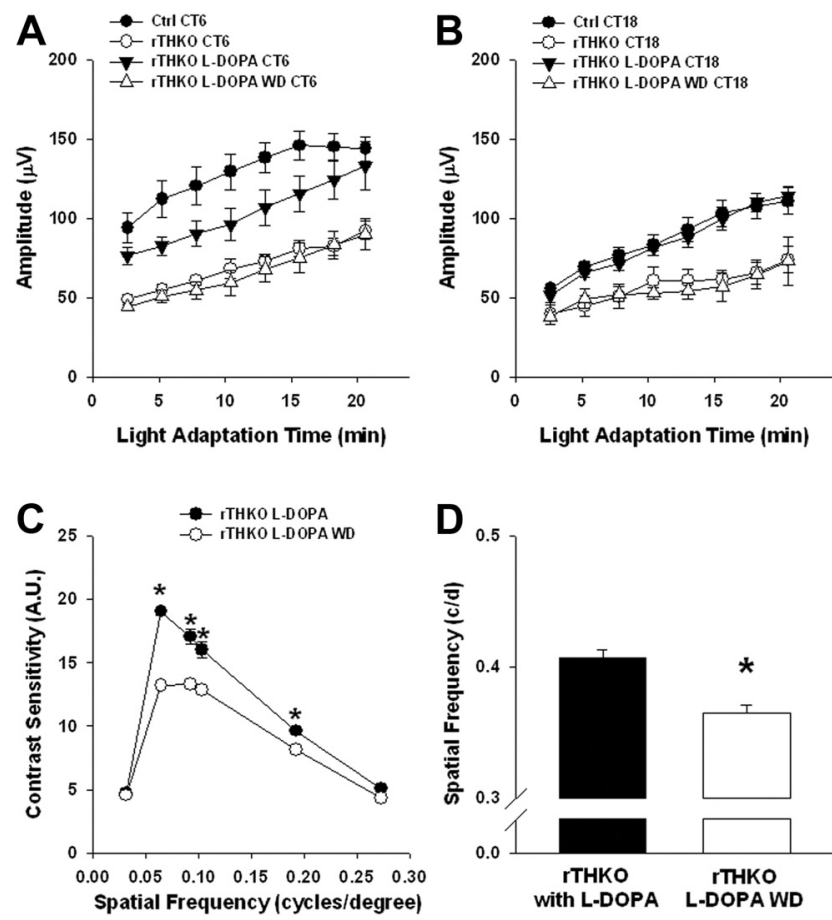

Figure 6. L-DOPA treatment rescues visual phenotype in dopamine-deficient mice. $\boldsymbol{A}, \boldsymbol{B}$, Light-adapted ERG analysis of (trl (filled circles), rTHKO (open circles), L-DOPA-treated rTHKO (filled triangles), and L-DOPA withdrawn (WD) rTHKO (open triangles) mice showed that L-DOPA treatment partially restored the b-wave amplitude at CT6 and CT18. A significant two-way interaction was found for Genotype (with treatment) $\times C \mathrm{CT}\left(F_{(3,90)}=25.4, p<0.01\right)$. Significant day/night differences were revealed for Ctrl, rTHKO, and rTHKO-L-DOPA groups using post hoc comparisons (CT6 vs CT18 for each tested group; $p<0.001, p<0.01$, and $p<0.01$, respectively), with no difference detected in the rTHKO-WD group. It is noted that the rTHKO group in this experiment, under this analysis, displayed a significant day/night difference; however, its response amplitude is significantly decreased compared with the day/night difference of the Ctrl group (Bonferroni-corrected alpha, $p<0.001$ ). C, Visual contrast sensitivity was preserved with L-DOPA treatment in rTHKO mice when compared with the same mice that had L-DOPA treatment withdrawn from their regimen ${ }^{*} p<0.05$; two-way ANOVA, post hoc student Newman-Kuels; $n=4-8$ mice). $\boldsymbol{D}, \mathrm{L}$-DOPA treatment maintained visual acuity threshold levels in rTHKO mice $\left({ }^{*} p<0.05 ; t\right.$ test; $n=6-8$ mice). All data are represented as means $\pm S E M$.

(Fig. 7A; Genotype main effect; $p<0.01$ ). Moreover, circadian regulation of the light-adapted ERG in D4RKO mice was abolished by DD2 (Fig. 7B; Genotype $\times$ CT interaction; $p<0.01$ ), with day-phase CT6 amplitudes reduced to night-phase CT18 levels. In contrast to D4RKO mice, light-adapted ERG circadian regulation in D1RKO mice was similar to WT mice during DD2 (Fig. $7 C$ ) with elevated b-wave amplitudes at CT6. However, while the rhythm was intact, the baseline amplitude of the light-adapted ERG was reduced in D1RKO mice, in agreement with recently published data (Herrmann et al., 2011). These data suggest that specific activation of the $\mathrm{D} 4$ receptor is necessary for circadian regulation of the light-adapted ERG. To test whether activation of $\mathrm{D} 4$ receptors is sufficient for circadian light-adapted ERG regulation, rTHKO mice were injected at subjective dawn on DD1 and DD2 with the selective D4 receptor agonist PD168077 (2 mg/kg; i.p. injection) and, subsequently, light-adapted ERGs were recorded. PD168077 restored circadian regulation of the light-adapted b-wave during DD2 by increasing response amplitude at CT6 compared with rTHKO saline-treated controls (Fig. 7D; Treatment $\times$ CT interaction, $p<$ 0.05; CT6 vs CT18, rTHKO PD168077 treated, $p<0.001$; rTHKO saline treated, $p=0.89$ ).

D4RKO mice exhibited significantly lower CSF levels compared with WT controls over multiple spatial frequencies (Fig. 


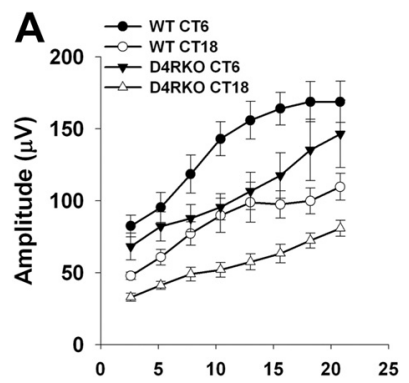

Light Adaptation Time (min) DD1

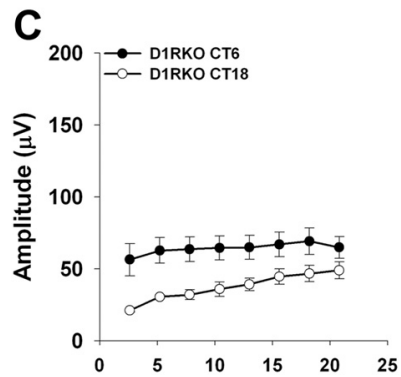

Light Adaptation Time ( $\mathrm{min}) \mathrm{DD} 2$

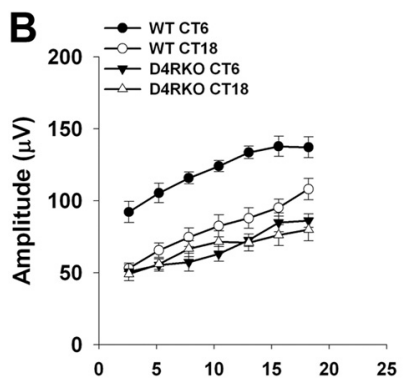

Light Adaptation Time (min) DD2

D

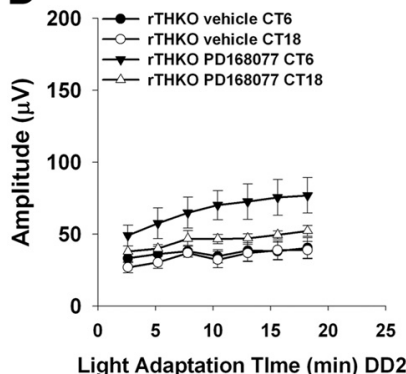

Figure 7. Dopamine receptor signaling supports the amplitude and circadian rhythm of the light-adapted b-wave ERG response. $A$, During DD1 a three-way ANOVA revealed significant main effects of Light Adaptation $\left(F_{(7,94)}=35.7, p<0.01\right)$, Genotype $\left(F_{(1,68)}=117.2, p<\right.$ $0.01)$, and $\mathrm{CT}\left(F_{(1,27)}=83.8, p<0.01\right)$. $\boldsymbol{B}$, During DD2 similar significant main effects were observed, with a significant tw0-way interaction found for Genotype $\times \mathrm{CT}\left(F_{(1,18)}=24.3, p<\right.$ 0.01). Post hoc analysis (Tukey's HSD) revealed significant differences for the WT (circles) CT6 group versus all other groups, including WT CT18 $(p<0.01)$. Also, the WT CT18 group showed greater amplitude than the D4RKO group (triangles) at either CT ( $p<0.01$ for both). For D4RKO mice, there was no significant difference in b-wave amplitudes between CT6 and CT18 ( $p>$ 0.05). C, D1RKO mice retained significant circadian regulation of the light-adapted ERG as measured by two-way ANOVA ( $p<0.001, n=3-6$ ); however, there was an apparent drop in amplitude compared with wild-type mice in other experiments. $D$, A significant two-way interaction was found for TreatmentGroup $\times C \mathrm{CT}\left(F_{(1,14)}=13.9, p<0.05\right)$. Posthocanalysis showed a significant day/night difference for the rTHKO group treated with PD168077 (filled and open triangles; $p<0.01$ ); however, the same genotype of mouse treated with saline displayed no difference (filled and open circles; $p=$ 0.89). Data are represented as means \pm SEM.

$8 A ;{ }^{\star} p<0.001$ at $0.031,0.064,0.092,0.103$, and 0.192 cycles/ degree, respectively, and ${ }^{\star} p=0.038$ at 0.272 cycles/degree). Conversely, D1RKO mice showed no deficits in their CSFs, and in fact showed small increases of contrast sensitivity at high spatial frequencies compared with control mice (Fig. $8 B$; ${ }^{*} p<0.05$ ). Treatment of rTHKO mice with PD168077 (1 mg/kg; i.p. injection) restored contrast sensitivity levels compared with rTHKO salinetreated controls (Fig. $8 C$; ${ }^{\star} p<0.001$ at $0.064,0.92$, and 0.103 cycles/degree). CSFs in rTHKO mice treated with PD168077 were similar to the Ctrl saline group.

D1RKO mice exhibited significantly lower visual acuity threshold (Fig. $8 D ;{ }^{*} p<0.05$ ), while D4RKO mice showed spatial resolution thresholds similar to WT mice. Treatment of rTHKO mice with the D1 receptor agonist SKF38393 $(1 \mathrm{mg} / \mathrm{kg}$; i.p. injection) rescued visual acuity (Fig. $8 D ;{ }^{* *} p<0.001$ ). Interestingly, treatment of rTHKO mice with PD168077 had no effect on visual acuity threshold and treatment with SKF38393 had no effect on contrast sensitivity, further demonstrating the receptor specificity of these pathways (Fig. $8 C, D$ ). Together, these data suggest that dopamine D1 and D4 receptors differentially regulate distinct actions of dopamine on retinal function, with activation of D1 receptors being necessary and sufficient to maintain high spatial resolution, and activation of D4 receptors being nec-

A
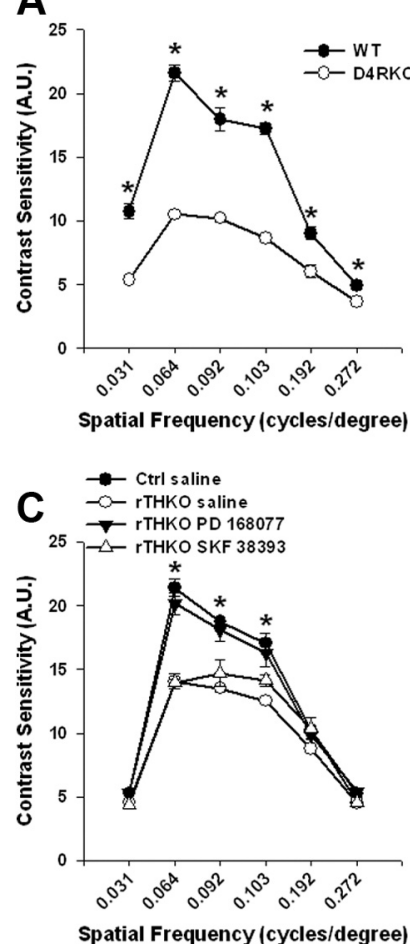

B

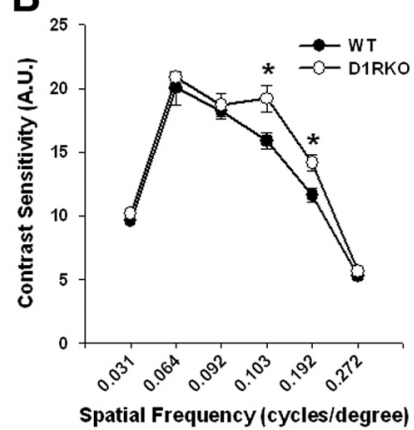

D

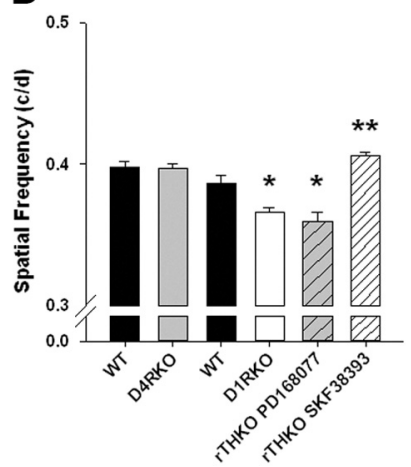

Figure 8. Dopamine receptors modulate contrast sensitivity and visual acuity threshold in mice. $\boldsymbol{A}$, D4RKO mice displayed significant decreases of contrast sensitivity detection at all spatial frequencies tested $\left({ }^{*} p<0.001\right.$ at $0.031,0.064,0.092,0.103,0.192$, and 0.272 cycles/ degree, Student-Newman-Keuls post hoc test, $n=4-6$ mice). $\boldsymbol{B}$, Contrast sensitivity measurements in D1RK0 mice were similar to WT controls, except at 0.103 and 0.192 cycles/degree $\left({ }^{*} p<0.05\right.$; Student-Newman-Keuls, $n=4-6$ mice) where significant increases were observed. C, Injecting rTHKO mice with SKF38393 did not increase contrast sensitivity levels; however, injection of PD168077 significantly increased contrast sensitivity levels in rTHKO mice (filled triangles; ${ }^{*} p<0.001$ at $0.064,0.092$, and 0.103 cycles/degree; Student-NewmanKeuls method, $n=4-6$ mice). $\boldsymbol{D}$, Visual acuity levels were lower in D1RKO mice and mice deficient in retinal dopamine, as measured by increasing spatial frequency of a sine-wave gradient, as compared with WT controls and D4RKO mice ( ${ }^{*} p=0.002 ; n=4$ mice). Intraperitoneal injection of SKF38393 significantly increased visual acuity in rTHKO mice $\left({ }^{* *} p<0.001\right.$; Student-Newman-Keuls method, $n=4-6$ mice), while PD168077 failed to have any effect on acuity in mice lacking retinal dopamine. Data are represented as means \pm SEM.

essary to maintain high daytime amplitudes of the light-adapted ERG and contrast sensitivity.

\section{Discussion}

Here, we developed a mouse model in which $\mathrm{TH}$ is specifically disrupted in the retina, resulting in retina-specific dopamine depletion. We used noninvasive electrophysiological and psychophysical techniques in intact mice to assess the overall role of retinal dopamine in vision and found that retinal dopamine is necessary for high-resolution, light-adapted vision mediated through dopamine D1 and D4 receptors.

\section{Retinal dopamine supports multiple dimensions of light-adapted vision}

Light-adapted vision is mediated by the cone system of the retina and in the natural environment occurs during the light of the day when high luminance and high contrast provide the basis for high-resolution vision. Our results indicate that dopamine reconfigures the retina for daytime vision enhancing contrast sensitivity and high spatial resolution. While dark-adapted ERGs were normal in rTHKO mice, light-adapted ERGs were reduced 
in amplitude and their circadian regulation disrupted by reduction of daytime b-wave amplitudes to nighttime levels. Also, CSF and visual acuity thresholds were degraded in rTHKO mice.

Retinal dopamine signaling is elevated in the circadian day, either as a consequence of rhythmic dopamine secretion driven by the retinal circadian clock (Witkovsky, 2004), or as a result of diurnal or circadian rhythms in dopamine $\mathrm{D} 4$ receptor gene expression (Storch et al., 2007; Bai et al., 2008; Klitten et al., 2008; Jackson et al., 2011). In the light/dark cycles, light-induced dopamine utilization would also enhance dopamine signaling during the day (Witkovsky, 2004).

\section{Dopamine D4 receptors regulate light-adapted ERG rhythms and contrast sensitivity}

The D4 receptor regulates the b-wave amplitude and the circadian rhythmicity of the light-adapted ERG and CSF, but does not appear to impact acuity. Dopamine has been previously shown to act through D4 receptors to drive retinal rhythms in cAMP metabolism and adenylyl cyclase gene expression (Jackson et al., 2011). Here we have shown that the dopamine D4 receptor signaling pathway is necessary and sufficient to connect retinal circadian regulation to key aspects of retinal function and to promote the daytime elevation of the light-adapted ERG, while also regulating contrast responses. Interestingly, full loss of lightadapted $b$-wave amplitude and its circadian regulation does not occur until the second day in constant darkness in rTHKO mice. However, low levels of dopamine and numbers of TH-expressing cells in rTHKO mouse retinas suggest the possibility that some residual dopamine signaling could be retained in rTHKO mouse retinas. The residual dopamine could be due to either incomplete action of Chx10-Cre in all retinal cells or availability of L-DOPA provided by tyrosinase (Rios et al., 1999). The amplitudes of dopamine and $\mathrm{D} 4$ receptor expression rhythms in mouse retina are highest in light/dark cycles and decline in DD (Doyle et al., 2002; Jackson et al., 2011). Thus, the time course of loss of circadian regulation by $\mathrm{D} 4$ receptor signaling observed may reflect either the time course of loss of synchrony in retinal cell populations proposed to be coupled by D4 receptors (Jackson et al., 2011), or the time course of decline in residual dopamine signaling connecting the retinal circadian clock to the light-adapted ERG. D2 receptor knock-out mice show compromised retinal circadian molecular rhythms and circadian light responses (Yujnovsky et al., 2006). Although we do not exclude a role for D2 receptors in the visual processes we have measured, our data indicate that the full effects of dopamine depletion can be accounted for by $\mathrm{D} 4$ and $\mathrm{D} 1$ receptor mechanisms.

rTHKO mice showed loss of circadian light-adapted ERG regulation similar to cryptochrome 1 and 2 knock-out mice (Cry $1^{-/-} \mathrm{Cry}^{2^{-/-}}$), retinal-specific Bmall knock-out mice, and melanopsin knock-out mice (Barnard et al., 2006; Storch et al., 2007; Cameron et al., 2008a). Cry $1^{-/-} \mathrm{Cr} y 2^{-/-}$and Bmall knock-out mice lack functional retinal circadian clocks (Storch et al., 2007; Cameron et al., 2008a) in contrast to rTHKO mice and melanopsin knock-out mice (our unpublished observations) in which retinal molecular circadian rhythms are still intact. Moreover, melanopsin-expressing, intrinsically photoreceptive retinal ganglion cells provide excitatory drive to dopamine neurons in a novel intraretinal retrograde signaling pathway (Zhang et al., 2008). Thus, in melanopsin knock-out mice there may be disruption of light input from intrinsically photosensitive retinal ganglion cells to dopaminergic amacrine cells leading to loss of dopamine output or circadian synchronization among dopamine neurons.

\section{Dopamine D1 receptors support high spatial resolution and high amplitude light-adapted ERGs}

Dopamine acting through D1 receptors is necessary and sufficient to maintain retinal spatial resolution, but interruption of D1 receptor signaling did not impact circadian regulation of the light-adapted ERG. The lack of impact of D1 receptor signaling on circadian regulation of retinal function is in agreement with previous findings demonstrating that D1 receptor-dependent regulation of horizontal cell gap junctional coupling is not circadianregulated, but requires light-induced dopamine release, whereas photoreceptor gap junction coupling, which is mediated by D2-like family receptors, is circadian regulated (Ribelayga and Mangel, 2003; Ribelayga et al., 2008).

The reduction in the baseline of the D1RKO light-adapted ERG data supports recent findings showing dopamine acts via D1 receptors affecting GABA release, elevating the ON-bipolar cell response in the presence of background illumination (Herrmann et al., 2011). Circadian regulation of the light-adapted ERG is, however, still intact in D1RKO mice. Thus, with respect to their effects on retinal light responses, both D4 and D1 receptors act to increase the amplitude of the light-adapted ERG b-wave, with D4 receptors acting through circadian regulation of the ERG and D1 receptors acting on baseline amplitude in a non-circadian manner. This differential regulation using two receptor signaling streams allows distinct control of circadian timing as well as lightadapted ERG amplitude.

\section{Dopamine signaling and retinal function}

From our findings and published results, we propose that dopamine acting on dopamine D1 receptors on cone ON-bipolar/ horizontal cells and dopamine D4 receptors on photoreceptor cells coordinates multiple levels of light-adapted vision. Dopamine D1 receptors have shown to be expressed on horizontal cells and cone ON-bipolar cells (Veruki and Wässle, 1996; NguyenLegros et al., 1997). Our results identified D1 receptor signaling as primarily supporting two specific aspects of light-adapted vision: high acuity and ERG b-wave amplitude. An obvious speculation is that D1 receptor signaling in cone ON-bipolar cells that are involved in generating the light-adapted ERG b-wave may mediate the effects on light-adapted ERG amplitude.

D1 receptors modulate horizontal cell coupling through gap junctions in a wide range of species, including mammals and primates (Xin and Bloomfield, 1999; He et al., 2000; Zhang et al., 2011), acting to uncouple horizontal cells, restrict current flow across their electrical synapses, and shrink their receptive fields. Although the relationship between horizontal cell receptive fields and the center-surround structure of ganglion cell-receptive fields is still poorly understood, a conventional interpretation is that horizontal cells contribute to ganglion cell inhibitory surrounds (but see Dedek et al., 2008). Therefore, a loss of dopamine signaling could expand horizontal cell-receptive fields through increased coupling and, in turn, expand ganglion cell-receptive field surrounds to shift the tuning of ganglion cell responses toward lower spatial frequencies.

In the retina $\mathrm{D} 4$ receptors are principally concentrated in cone photoreceptors where they are known to affect cAMP metabolism, gene expression, and rod-cone gap junctional coupling (Cohen et al., 1992; Ribelayga et al., 2008; Jackson et al., 2011). They play a critical role in circadian modulation of rod-cone coupling, enhancing transmission of rod signals into cones and cone pathways in the night phase of retinal circadian rhythms when dopamine is low (Ribelayga et al., 2008). Increased rodcone coupling in the absence of dopamine may shunt cone light 
responses into rods under rod-saturating backgrounds, reducing the light-adapted ERG b-wave. Similarly, the sharing of rod and cone signals through enhanced coupling in the absence of dopamine may reduce the CSF of ganglion cell centers, and thus dampen the overall contrast sensitivity.

In addition to dopamine, retinal melatonin is an important circadian signal in the retina that has a reciprocal and antagonistic relationship with dopamine (Nguyen-Legros et al., 1996; Tosini and Dirden, 2000). Melatonin type 1 receptor knock-out blunts the circadian rhythm in light-adapted ERG b-wave amplitude in C3H mice (Sengupta et al., 2011) without affecting levels of dopamine and DOPAC. Mice in our study were on the C57BL/6 background in which melatonin synthesis is minimal. Thus our results show the actions of dopamine on the lightadapted ERG b-wave response and other visual responses without any potential antagonism from melatonin. Further testing will be required to determine the mechanisms of dopaminemelatonin interactions in circadian regulation of retinal function.

In conclusion, we have described a mouse model in which retinal dopamine is selectively depleted and which reveals specific deficits in light-adapted vision. This mouse model should be useful in delineating the underlying mechanisms by which retinal dopamine reconfigures retinal circuits according to $\mathrm{CT}$ and background illumination.

\section{References}

Abremski K, Hoess R (1984) Bacteriophage P1 site-specific recombination. Purification and properties of the Cre recombinase protein. J Biol Chem 259:1509-1514.

Bai L, Zimmer S, Rickes O, Rohleder N, Holthues H, Engel L, Leube R, Spessert R (2008) Daily oscillation of gene expression in the retina is phase-advanced with respect to the pineal gland. Brain Res 1203:89-96.

Barnard AR, Hattar S, Hankins MW, Lucas RJ (2006) Melanopsin regulates visual processing in the mouse retina. Curr Biol 16:389-395.

Bodis-Wollner I (1990a) Visual deficits related to dopamine deficiency in experimental animals and Parkinson's disease patients. Trends Neurosci 13:296-302.

Bodis-Wollner I (1990b) The visual system in Parkinson's disease. Res Publ Assoc Res Nerv Ment Dis 67:297-316.

Cameron MA, Barnard AR, Hut RA, Bonnefont X, van der Horst GT, Hankins MW, Lucas RJ (2008a) Electroretinography of wild-type and Cry mutant mice reveals circadian tuning of photopic and mesopic retinal responses. J Biol Rhythms 23:489-501.

Cameron MA, Barnard AR, Lucas RJ (2008b) The electroretinogram as a method for studying circadian rhythms in the mammalian retina. J Genet $87: 459-466$.

Cohen AI, Todd RD, Harmon S, O’Malley KL (1992) Photoreceptors of mouse retinas possess D4 receptors coupled to adenylate cyclase. Proc Natl Acad Sci U S A 89:12093-12097.

Day M, Wokosin D, Plotkin JL, Tian X, Surmeier DJ (2008) Differential excitability and modulation of striatal medium spiny neuron dendrites. J Neurosci 28:11603-11614.

Dedek K, Pandarinath C, Alam NM, Wellershaus K, Schubert T, Willecke K, Prusky GT, Weiler R, Nirenberg S (2008) Ganglion cell adaptability: does the coupling of horizontal cells play a role? PLoS One 3:e1714.

Diehl DJ, Gershon S (1992) The role of dopamine in mood disorders. Compr Psychiatry 33:115-120.

Doyle SE, McIvor WE, Menaker M (2002) Circadian rhythmicity in dopamine content of mammalian retina: role of the photoreceptors. J Neurochem 83:211-219.

Farley FW, Soriano P, Steffen LS, Dymecki SM (2000) Widespread recombinase expression using FLPeR (flipper) mice. Genesis 28:106-110.

Graw J (1996) Genetic aspects of embryonic eye development in vertebrates. Dev Genet 18:181-197.

Hamilton DL, Abremski K (1984) Site-specific recombination by the bacteriophage P1 lox-Cre system. Cre-mediated synapsis of two lox sites. J Mol Biol 178:481-486.

He S, Weiler R, Vaney DI (2000) Endogenous dopaminergic regulation of horizontal cell coupling in the mammalian retina. J Comp Neurol 418:33-40.

Herrmann R, Heflin SJ, Hammond T, Lee B, Wang J, Gainetdinov RR, Caron MG, Eggers ED, Frishman LJ, McCall MA, Arshavsky VY (2011) Rod Vision Is Controlled by Dopamine-Dependent Sensitization of Rod Bipolar Cells by GABA. Neuron 72:101-110.

Ikemoto S, Glazier BS, Murphy JM, McBride WJ (1997) Role of dopamine D1 and D2 receptors in the nucleus accumbens in mediating reward. J Neurosci 17:8580-8587.

Iuvone PM, Galli CL, Garrison-Gund CK, Neff NH (1978) Light stimulates tyrosine hydroxylase activity and dopamine synthesis in retinal amacrine neurons. Science 202:901-902.

Iuvone PM, Tosini G, Pozdeyev N, Haque R, Klein DC, Chaurasia SS (2005) Circadian clocks, clock networks, arylalkylamine N-acetyltransferase, and melatonin in the retina. Prog Retin Eye Res 24:433-456.

Jackson CR, Chaurasia SS, Zhou H, Haque R, Storm DR, Iuvone PM (2009) Essential roles of dopamine D4 receptors and the type 1 adenylyl cyclase in photic control of cyclic AMP in photoreceptor cells. J Neurochem 109:148-157.

Jackson CR, Chaurasia SS, Hwang CK, Michael Iuvone PM (2011) Dopamine $\mathrm{D}(4)$ receptor activation controls circadian timing of the adenylyl cyclase 1/cyclic AMP signaling system in mouse retina. Eur J Neurosci 34:57-64.

Klitten LL, Rath MF, Coon SL, Kim JS, Klein DC, Møller M (2008) Localization and regulation of dopamine receptor D4 expression in the adult and developing rat retina. Exp Eye Res 87:471-477.

Kulisevsky J (2000) Role of dopamine in learning and memory: implications for the treatment of cognitive dysfunction in patients with Parkinson's disease. Drugs Aging 16:365-379.

Lorea I, Fernández-Montalvo J, Tirapu-Ustárroz J, Landa N, López-Goñi JJ (2010) Neuropsychological performance in cocaine addiction: a critical review. Rev Neurol 51:412-426.

Masson G, Mestre D, Blin O (1993) Dopaminergic modulation of visual sensitivity in man. Fundam Clin Pharmacol 7:449-463.

Nguyen-Legros J, Chanut E, Versaux-Botteri C, Simon A, Trouvin JH (1996) Dopamine inhibits melatonin synthesis in photoreceptor cells through a D2-like receptor subtype in the rat retina: biochemical and histochemical evidence. J Neurochem 67:2514-2520.

Nguyen-Legros J, Simon A, Caillé I, Bloch B (1997) Immunocytochemical localization of dopamine D1 receptors in the retina of mammals. Vis Neurosci 14:545-551.

Orban PC, Chui D, Marth JD (1992) Tissue- and site-specific DNA recombination in transgenic mice. Proc Natl Acad Sci U S A 89:6861-6865.

Pozdeyev N, Tosini G, Li L, Ali F, Rozov S, Lee RH, Iuvone PM (2008) Dopamine modulates diurnal and circadian rhythms of protein phosphorylation in photoreceptor cells of mouse retina. Eur J Neurosci 27:2691-2700.

Prusky GT, Alam NM, Beekman S, Douglas RM (2004) Rapid quantification of adult and developing mouse spatial vision using a virtual optomotor system. Invest Ophthalmol Vis Sci 45:4611-4616.

Prusky GT, Alam NM, Douglas RM (2006) Enhancement of vision by monocular deprivation in adult mice. J Neurosci 26:11554-11561.

Ribelayga C, Mangel SC (2003) Absence of circadian clock regulation of horizontal cell gap junctional coupling reveals two dopamine systems in the goldfish retina. J Comp Neurol 467:243-253.

Ribelayga C, Cao Y, Mangel SC (2008) The circadian clock in the retina controls rod-cone coupling. Neuron 59:790-801.

Rios M, Habecker B, Sasaoka T, Eisenhofer G, Tian H, Landis S, Chikaraishi D, Roffler-Tarlov S (1999) Catecholamine synthesis is mediated by tyrosinase in the absence of tyrosine hydroxylase. J Neurosci 19:3519-3526.

Rowan S, Cepko CL (2004) Genetic analysis of the homeodomain transcription factor Chx10 in the retina using a novel multifunctional BAC transgenic mouse reporter. Dev Biol 271:388-402.

Ruan GX, Allen GC, Yamazaki S, McMahon DG (2008) An autonomous circadian clock in the inner mouse retina regulated by dopamine and GABA. PLoS Biol 6:e249.

Rubinstein M, Phillips TJ, Bunzow JR, Falzone TL, Dziewczapolski G, Zhang G, Fang Y, Larson JL, McDougall JA, Chester JA, (1997) Mice lacking dopamine D4 receptors are supersensitive to ethanol, cocaine, and methamphetamine. Cell 90:991-1001.

Sengupta A, Baba K, Mazzoni F, Pozdeyev NV, Strettoi E, Iuvone PM, Tosini G (2011) Localization of melatonin receptor 1 in mouse retina and its 
role in the circadian regulation of the electroretinogram and dopamine levels. PLoS ONE 6:e24483.

Snyder SH (1976) The dopamine hypothesis of schizophrenia: focus on the dopamine receptor. Am J Psychiatry 133:197-202.

Stanwood GD, Parlaman JP, Levitt P (2005) Anatomical abnormalities in dopaminoceptive regions of the cerebral cortex of dopamine D1 receptor mutant mice. J Comp Neurol 487:270-282.

Storch KF, Paz C, Signorovitch J, Raviola E, Pawlyk B, Li T, Weitz CJ (2007) Intrinsic circadian clock of the Mammalian retina: importance for retinal processing of visual information. Cell 130:730-741.

Taylor TN, Caudle WM, Shepherd KR, Noorian A, Jackson CR, Iuvone PM, Weinshenker D, Greene JG, Miller GW (2009) Nonmotor symptoms of Parkinson's disease revealed in an animal model with reduced monoamine storage capacity. J Neurosci 29:8103-8113.

Tosini G, Dirden JC (2000) Dopamine inhibits melatonin release in the mammalian retina: in vitro evidence. Neurosci Lett 286:119-122.

Veruki ML, Wässle H (1996) Immunohistochemical localization of dopamine D1 receptors in rat retina. Eur J Neurosci 8:2286-2297.
Witkovsky P (2004) Dopamine and retinal function. Doc Ophthalmol 108:17-40.

Xin D, Bloomfield SA (1999) Dark- and light-induced changes in coupling between horizontal cells in mammalian retina. J Comp Neurol 405: $75-87$.

Yoo SH, Yamazaki S, Lowrey PL, Shimomura K, Ko CH, Buhr ED, Siepka SM, Hong HK, Oh WJ, Yoo OJ, (2004) PERIOD2::LUCIFERASE real-time reporting of circadian dynamics reveals persistent circadian oscillations in mouse peripheral tissues. Proc Natl Acad Sci U S A 101:5339-5346.

Yujnovsky I, Hirayama J, Doi M, Borrelli E, Sassone-Corsi P (2006) Signaling mediated by the dopamine $\mathrm{D} 2$ receptor potentiates circadian regulation by CLOCK:BMAL1. Proc Natl Acad Sci U S A 103:6386-6391.

Zhang AJ, Jacoby R, Wu SM (2011) Light- and dopamine-regulated receptive field plasticity in primate horizontal cells. J Comp Neurol 519:2125-2134.

Zhang DQ, Wong KY, Sollars PJ, Berson DM, Pickard GE, McMahon DG (2008) Intraretinal signaling by ganglion cell photoreceptors to dopaminergic amacrine neurons. Proc Natl Acad Sci U S A 105: 14181-14186. 